\title{
Early Screening of Hemoglobinopathy in Indonesia Using Erythrocyte Indices
}

\author{
Yenny Surjawan ${ }^{1, *}$, Hwee Lian Tan ${ }^{1}$, Rahajuningsih Dharma Setiabudy ${ }^{1,2}$, Wiwik Rositawati ${ }^{1}$ \\ 'Prodia Clinical Laboratory, Jl. Kramat Raya No. 150, Jakarta, Indonesia \\ ${ }^{2}$ Cipto Mangunkusumo Hospital, Jl. Pangeran Diponogoro No. 170, Jakarta, Indonesia \\ *Corresponding author. E-mail: yensurjawan@yahoo.com
}

Received date: Feb 17, 2017; Revised date: May 24, 2017; Accepted date: May 29, 2017

\section{Abstract}

$\mathrm{B}$ ACKGROUND: The mutation spectrums of hemoglobinopathy are different among populations that yield a different result of erythrocyte indices. Calculation of erythrocyte indices with some formula has been reported to differentiate between hemoglobinopathy and non-hemoglobinopathy, but its cut-off should be recalculated specific for each population to gain a better sensitivity and specificity. We aimed to evaluate red blood cell count (RBC), Mentzer index, red cell distribution width (RDW), RDW index (RDWI), Shine and Lal index (S\&L) and Green and King index (G\&K) to screen hemoglobinopathy in Indonesia.

METHODS: A retrospective cross-sectional study was performed on 202 subjects. The diagnosis of hemoglobinopathy was determined based on the results of complete blood count (CBC) data, high-performance liquid chromatography (HPLC) and Hemoglobin $\mathrm{H}(\mathrm{HbH})$ inclusion body. The ferritin concentration was checked to determine the status of iron. The erythrocytes indices were analyzed and calculated to predict hemoglobinopathy.
RESULTS: A total 202 subjects who met the criteria were involved in this study. Fifty percent showed pure hemoglobinopathy and 4\% showed a combination of thalassemia and hemoglobinopathy. The hemoglobin concentration and $\mathrm{RBC}$ were significantly higher, and the mean corpuscular volume (MCV) and RDW were significantly lower in hemoglobinopathy compared to iron deficiency. The difference was not significant if the hemoglobinopathy was combined with iron deficiency. By this study's cut-off, the G\&K and RDWI showed the highest accuracy, sensitivity, and specificity.

CONCLUSION: The new cut-off of erythrocyte index and its calculation to screen hemoglobinopathy in Indonesia showed a higher sensitivity and specificity, especially for G\&K and RDWI with cut-off 73 and 228, respectively. The presence of iron deficiency in hemoglobinopathy could decrease the sensitivity.

KEYWORDS: hemoglobinopathy, RBC, Mentzer index, RDW, RDWI, S\&L, G\&K

Indones Biomed J. 2017; 9(2): 99-105

\section{Introduction}

Hemoglobinopathy, which consists of thalassemia and hemoglobin variant (1), is the most frequent genetic disorder found in the world. Its prevalence in Indonesia is about $10 \%$. A screening program has been proposed to prevent an increasing number or new case of thalassemia.(2)

Early screening of hemoglobinopathy using complete blood count (CBC) generally shows a normal or slightly decrease of hemoglobin level with a low mean corpuscular volume (MCV) and mean corpuscular hemoglobin (MCH), but a high red blood cell distribution width (RDW). These characteristics are not only found in hemoglobinopathy, but it also could be found in iron deficiency and chronic disease. The treatment of these three conditions is not similar, whereas iron supplementation is indicated for iron deficiency, but it is not indicated for hemoglobinopathy and chronic disease.(3) Therefore, further examinations, such as iron level, total iron binding capacity (TIBC), ferritin, 
evaluation of hemoglobin $\mathrm{A}_{2}\left(\mathrm{HbA}_{2}\right)$, hemoglobin $\mathrm{F}(\mathrm{HbF})$, and the presence of an abnormal hemoglobin fraction should be performed.(4) However, the cost of these further examination is high and not all health care in Indonesia provide the facility to do all of these tests. Therefore, analysis of CBC result should be optimized.

Some formulas derived from erythrocytes indices have been reported to distinguish between thalassemia and other causes.(4-11) An appropriate cut-off of reported formulas should be redetermined to increase the sensitivity and specificity of thalassemia screening in one population because the spectrums of mutation of thalassemia are different among population which might result in different values of erythrocytes indices.(12-15) This study aimed to evaluate red blood cell count (RBC) and some formulas using erythrocytes indices, such as Mentzer index, RDW, RDW index (RDWI), Shine and Lal index (S\&L), and Green and King index (G\&K) for hemoglobinopathy screening in Indonesia.

\section{Methods}

This was a retrospective cross-sectional study that was performed in Prodia Clinical Laboratory (Jakarta, Indonesia) in 2015-2016 and the ethical clearance of this study had been approved by Medical Faculty of Trisakti University, with Ethical Number 73/KER/FK/III/2015.

Two hundred and two patients who underwent thalassemia screening and showed low $\mathrm{MCV}$ and $\mathrm{MCH}$ were recruited in this study. Subjects who had white blood cell count greater than $20 \%$ of its reference range, or had a history of blood transfusion within previous 3 months were excluded from this study.

The diagnosis of hemoglobinopathy was determined and classified by Clinical Pathologist based on an evaluation of $\mathrm{CBC}$ result, erythrocytes morphology, the presence of Hemoglobin $\mathrm{H}(\mathrm{HbH})$ inclusion bodies, and the result of hemoglobin fraction using high-performance liquid chromatography (HPLC) method. Beta thalassemia trait, if the erythrocyte showed microcytic hypochromic, low $\mathrm{MCV}$, low $\mathrm{MCH}$, and $\mathrm{HbA} 2$ fraction was between $3.5-5.0 \%$ or slightly greater in some case of mutation. Heterozygote Hemoglobin E (HbE) (trait), if the erythrocyte showed microcytic hypochromic, low MCV, low MCH, and $\mathrm{HbA}_{2}$ fraction was about $30 \%$. Beta-thalassemia/ $\mathrm{HbE}$ double heterozygote, if the erythrocyte was microcytic hypochromic, low $\mathrm{MCV}$, low $\mathrm{MCH}, \mathrm{HbA}_{2}$ was between 40-60\%, and $\mathrm{HbF}$ was between 5-87\%.(16) Alpha trait thalassemia, if the erythrocyte was slightly microcytic hypochromic, low $\mathrm{MCV}$, low $\mathrm{MCH}, \mathrm{HbA}_{2}$ fraction was normal or slightly decreased, $\mathrm{HbF}$ was generally normal, $\mathrm{Hb}$ Bart's as $0.8-11 \%$ could be present in the first 3 months of life, and $\mathrm{HbH}$ inclusion body could be found but very rare. $(1,16)$ Diagnosis of $\mathrm{HbH}$ disease was based on the presence of microcytic hypochromic erythrocyte, low $\mathrm{MCV}$, low $\mathrm{MCH}$, $\mathrm{HbA}_{2}$ was between $1-2 \%$, $\mathrm{HbF}$ was between 1-3.5\%, and a large amount of $\mathrm{HbH}$ inclusion bodies were found (35-90\% of RBC). The presence of alpha thalassemia trait could not be excluded if the erythrocyte was microcytic hypochromic, low $\mathrm{MCV}$, low $\mathrm{MCH}$, the $\mathrm{HbA}_{2}$ fraction was equal to or less than $3.5 \%$, but the $\mathrm{HbH}$ inclusion body was not found, and ferritin level was not decreased.(16) The presence of iron deficiency was determined if the ferritin level was less than the reference value. If hemoglobinopathy was present with iron deficiency, it was classified as a combination of hemoglobinopathy and iron deficiency.

Subject who classified as "combination of hemoglobinopathy and iron deficiency" or "alpha thalassemia trait could not be excluded" were not included for cut-off analysis. The CBC data from the instrument, such as hemoglobin concentration, $\mathrm{RBC}, \mathrm{MCV}, \mathrm{MCH}$ and RDW as part of routine hematology measurement were recorded. These data were used for some calculation of formulas to predict hemoglobinopathy, such as, (1) Mentzer index $=\mathrm{MCV} / \mathrm{RBC}$, (2) RDWI $=\mathrm{MCV} / \mathrm{RBC} \times \mathrm{RDW}$, (3) $\mathrm{S} \& \mathrm{~L}$ index $=\mathrm{MCV}^{2} \mathrm{x} \mathrm{MCH} \times 0.01$, (4) $\mathrm{G} \& \mathrm{~K}$ index $=\mathrm{MCV}^{2}$ $\mathrm{x}$ RDW / $(100 \times \mathrm{Hb}) .(8,11)$ The data was analyzed using IBM SPSS Statistics, version 22.

\section{Results}

Subjects involved in this study aged between 0.6-76 years old (mean 30 years old). The characteristics of the subjects were shown in Table 1.

The median of erythrocytes indices showed significant differences among groups (Figure 1). Hemoglobin concentration and $\mathrm{RBC}$ were significantly higher, but $\mathrm{MCV}$ and RDW were significantly lower in hemoglobinopathy compared to iron deficiency. But if the hemoglobinopathy was combined with iron deficiency, there were not any significant differences in these parameters between the subject with hemoglobinopathy only and subject with a combination of hemoglobinopathy and iron deficiency.

The cut-off of RBC, Mentzer index, RDW, RDWI, $S \& L$ and $G \& K$ were determined using receiver operating curve (ROC) (Table 2). To obtain the cut-off, we calculated 
Table 1. Characteristic of the subject $(n=202)$.

\begin{tabular}{|c|c|c|}
\hline Characteristic & $\mathbf{n}$ & $\%$ \\
\hline \multicolumn{3}{|l|}{ Gender } \\
\hline Male & 52 & 25.7 \\
\hline Female & 150 & 74.3 \\
\hline \multicolumn{3}{|l|}{ Etiology of microcytic hypochromic erythrocyte } \\
\hline Iron deficiency & 63 & 31.2 \\
\hline Hemoglobinopathy & 101 & 50.0 \\
\hline \multicolumn{3}{|l|}{ - Beta thalassemia trait $(\mathrm{n}=35)$} \\
\hline \multicolumn{3}{|l|}{ - Alpha thalassemia trait $(n=36)$} \\
\hline \multicolumn{3}{|l|}{ - HbE trait $(n=22)$} \\
\hline \multicolumn{3}{|l|}{ - Beta thalassemia/ HbE double heterozygote $(\mathrm{n}=2)$} \\
\hline \multicolumn{3}{|l|}{ - HbH disease $(n=6)$} \\
\hline Combination of hemoglobinopathy \& iron deficiency & 8 & 4.0 \\
\hline \multicolumn{3}{|l|}{ - Combination of beta thalassemia \& iron deficiency $(n=2)$} \\
\hline \multicolumn{3}{|l|}{ - Combination of alpha thalassemia \& iron deficiency $(n=1)$} \\
\hline \multicolumn{3}{|l|}{ - Combination of $\mathrm{HbE}$ trait \& iron deficiency $(\mathrm{n}=5)$} \\
\hline Alpha thalassemia trait could not be excluded & 30 & 14.9 \\
\hline
\end{tabular}

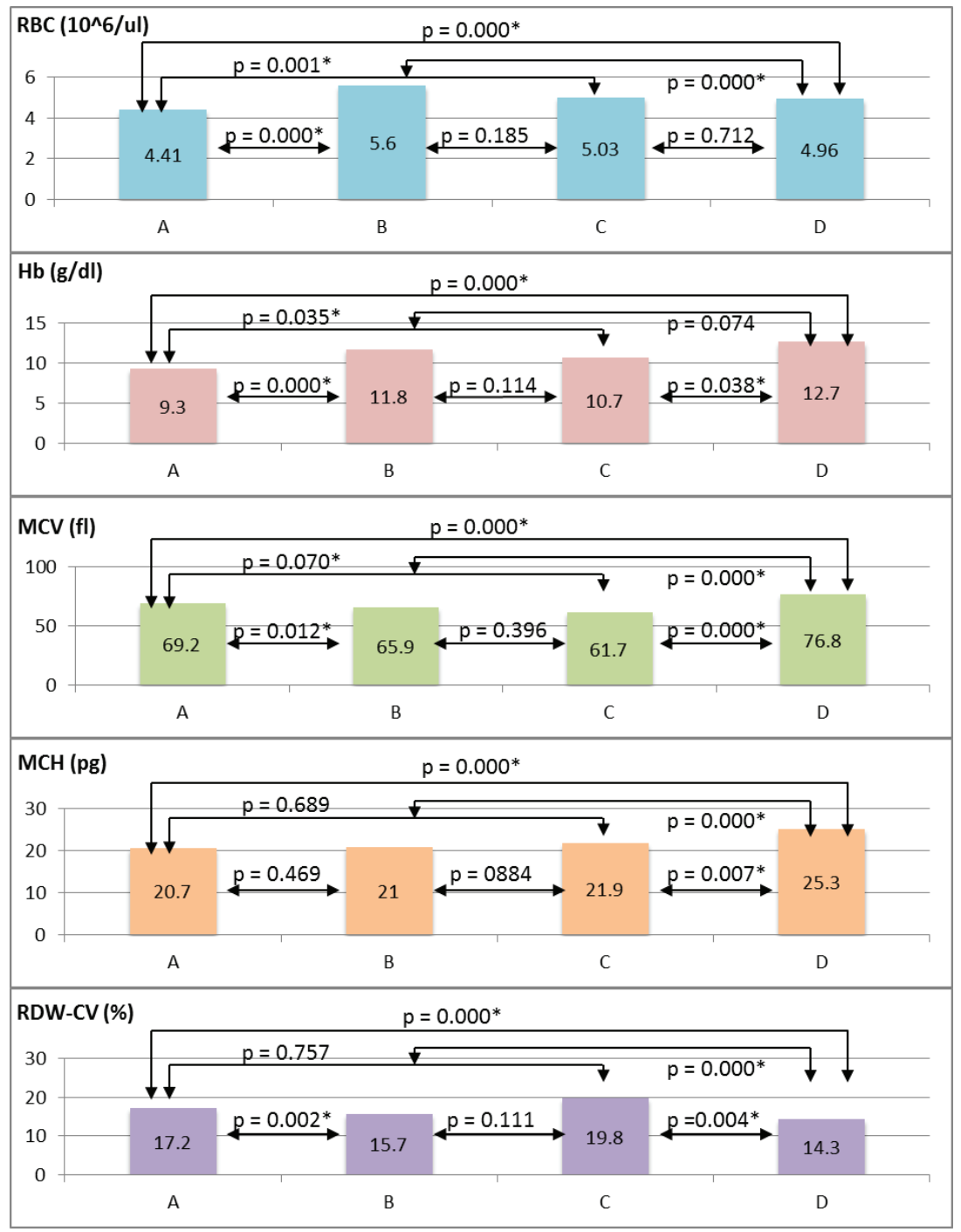

Figure 1. Comparison of median erythrocyte indices among groups of the subject. Note: $A=$ iron deficiency $(n=63)$; $B=$ hemoglobinopathy $(\mathrm{n}=101) ; \mathrm{C}=$ combination of hemoglobinopathy and iron deficiency $(\mathrm{n}=8) ; \mathrm{D}=$ alpha thalassemia trait could not be excluded $(n=30)$. 
164 data of 63 subjects with iron deficiency and 101 subjects with hemoglobinopathy. The highest accuracy to predict hemoglobinopathy was obtained with G\&K and RDWI (Table 3). There were $75 \%$ subjects with combination of hemoglobinopathy and iron deficiency that could be accurately identified by RBC or G\&K using our cut-off (Table 4). In subjects that we classified as could not be excluded for alpha thalassemia trait, there was a possibility of alpha thalassemia trait of 3.3-83.3\% based on erythrocyte index and its calculation (Table 5).

\section{Discussion}

Hemoglobinopathy (thalassemia or variant hemoglobin) is a genetic disorder of globin synthesis which is required for hemoglobin production. The clinical manifestation of hemoglobinopathy is varied, ranges from asymptomatic to symptoms that need repeated transfusion. Screening of hemoglobinopathy using $\mathrm{CBC}$ examination is very useful. Erythrocyte index from $\mathrm{CBC}$ data and its calculation with some formula could predict the possibility of beta thalassemia. If the result indicates a possibility of hemoglobinopathy, further analysis using other methods, such as electrophoresis, HPLC, or DNA analysis should be performed to confirm the result. Unfortunately, the cost of the test is quite high and the test does not always available in routine practice. $(3,15,17)$

This study involved 202 patients from many regions in Indonesia who underwent thalassemia screening and fulfilled the study's criteria. Most of the subjects were female $(74.3 \%)$. The most common etiology of microcytic hypochromic erythrocytes in this study was hemoglobinopathy (50\%); the others were iron deficiency $(31.2 \%)$, combination of hemoglobinopathy and iron deficiency (4\%) and $14.9 \%$ cases could not be excluded for alpha thalassemia trait (Table 1). Another study that involved 901 patients who had microcytic hypochromic erythrocyte and underwent thalassemia screening showed nearly similar result with ours, $49.2 \%$ subjects had beta thalassemia, and the rest were due to iron deficiency or other causes.(18)

Thalassemia patients usually show microcytic hypochromic erythrocytes with high RBC.(17) This study also showed a high median value of RBC (5.6 millions/ $\mu \mathrm{L})$. All erythrocyte indices showed significant differences between iron deficiency and hemoglobinopathy subjects, except $\mathrm{MCH}$ (Figure 1). The RBC and hemoglobin concentration were significantly higher, but the MCV and RDW were significantly lower in hemoglobinopathy compared to iron deficiency (hemoglobinopathy vs. iron deficiency: $\mathrm{RBC}=5.6$ vs. $4.4, \mathrm{Hb}=11.8$ vs. $9.3, \mathrm{MCV}=$ 65.9 vs. 69.2 , $\mathrm{RDW}=15.7$ vs. 17.2). This might be due

Table 2. The cut-off of erythrocytes indices and its sensitivity-specificity from literature and current study.

\begin{tabular}{lcccccc}
\hline & \multicolumn{3}{c}{ Literature } & \multicolumn{3}{c}{ Current Study } \\
\cline { 2 - 7 } Erythrocyte indices & Cut-off & $\begin{array}{c}\text { Sensitivity } \\
(\%)\end{array}$ & $\begin{array}{c}\text { Specificity } \\
(\%)\end{array}$ & Cut-off & $\begin{array}{c}\text { Sensitivity } \\
(\%)\end{array}$ & $\begin{array}{c}\text { Specificity } \\
(\%)\end{array}$ \\
\hline RBC & 5.0 & 79.0 & 90.0 & 4.7 & 84.0 & 81.0 \\
RDW & 14.0 & 12.0 & 87.0 & 16.5 & 63.0 & 59.0 \\
Mentzer index & 13.0 & 71.0 & 87.0 & 13.7 & 79.0 & 83.0 \\
RDWI & 220.0 & 85.0 & 95.0 & 228.0 & 88.0 & 92.0 \\
S\&L & 1530.0 & 98.0 & 8.0 & 954.0 & 55.0 & 56.0 \\
G\&K & 65.0 & 80.0 & 97.0 & 73.0 & 90.0 & 92.0 \\
\hline
\end{tabular}

Table 3. Percentage accuration to predict hemoglobinopathy obtained from literature and current study.

\begin{tabular}{lcccccc}
\hline & \multicolumn{3}{c}{ Literature } & \multicolumn{3}{c}{ Current Study } \\
\cline { 2 - 7 } Erythrocyte indices & $\begin{array}{c}\text { AUC } \\
\mathbf{( \% )}\end{array}$ & $\boldsymbol{p}$ & $\mathbf{9 5 \%} \mathbf{C I}$ & $\begin{array}{c}\text { AUC } \\
\mathbf{( \% )}\end{array}$ & $\boldsymbol{p}$ & $\mathbf{9 5 \%}$ CI \\
\hline RBC & 84.8 & 0.0 & $78.5-91.1$ & 82.6 & 0.0 & $75.6-89.5$ \\
RDW & 49.6 & 0.9 & $40.5-58,7$ & 61.0 & 0.0 & $52.1-70.0$ \\
Mentzer index & 79.3 & 0.0 & $72.2-86.4$ & 80.9 & 0.0 & $73.8-88.0$ \\
RDWI & 90.2 & 0.0 & $85.1-95.3$ & 90.1 & 0.0 & $84.8-95.4$ \\
S\&L & 53.0 & 0.5 & $43.8-62.2$ & 55.5 & 0.2 & $46.4-64.6$ \\
G\&K & 88.5 & 0.0 & $83.1-93.9$ & 91.1 & 0.0 & $85.9-96.2$ \\
\hline
\end{tabular}


Table 4. The percentage of correct prediction of hemoglobinopathy in subjects with combination of hemoglobinopathy and iron deficiency.

\begin{tabular}{lc}
\hline & $\begin{array}{c}\text { Hemoglobinopathy \& Iron Deficiency } \\
(\mathbf{n}=\mathbf{8})(\%)\end{array}$ \\
\hline RBC & 75.0 \\
RDW & 37.5 \\
Mentzer index & 62.5 \\
RDWI & 62.5 \\
S\&L & 62.5 \\
G\&K & 75.0 \\
\hline
\end{tabular}

Table 5. The percentage possibility of alpha thalassemia trait.

\begin{tabular}{lc}
\hline & $\begin{array}{c}\text { Alpha Thalassemia Trait Could Not Be Excluded } \\
(\mathbf{n}=\mathbf{3 0})(\mathbf{\%})\end{array}$ \\
\hline RBC & 70.0 \\
RDW & 83.3 \\
Mentzer index & 23.3 \\
RDWI & 63.3 \\
S\&L & 3.3 \\
G\&K & 70.0 \\
\hline
\end{tabular}

to in hemoglobinopathy the disorder happened only in hemoglobin synthesis, not in erythrocytes synthesis, but in iron deficiency, the disorder happened both in erythrocyte and hemoglobin synthesis.

Subjects with a combination of hemoglobinopathy and iron deficiency showed higher RBC and hemoglobin concentration compared to subjects with pure iron deficiency, but the MCV and RDW did not show a significant difference between both groups (combination of hemoglobinopathy and iron deficiency $v s$. iron deficiency: $\mathrm{RBC}=5.03$ vs. $4.41, \mathrm{Hb}=10.7$ vs. 9.3). But, the RBC and hemoglobin concentration within subjects with pure hemoglobinopathy (no combination with iron deficiency) were higher compared to those in subjects with combination of hemoglobinopathy and iron deficiency (Figure 1). It was suggested that the presence of iron deficiency in hemoglobinopathy patients influenced the $\mathrm{RBC}$ and hemoglobin concentration that yield a lower result compared to pure hemoglobinopathy.

Erythrocyte indices and their calculation could help to screen the diagnosis of thalassemia, especially beta thalassemia.(10) Thalassemia mutation spectrum in each population are not similar, so that the erythrocyte indices will be different among populations. Therefore, a cut-off in one population should be determined to increase the sensitivity and specificity of thalassemia.(12-15) In this study, we analyzed 164 data to determine the cut-off using ROC curve. There were different results in sensitivity and specificity between literature cut-off and this study cut-off (Table 2). Bordbar studied about this in Iran population who asked for premarital screening. The study showed that the new cut-off did not yield 100\% sensitivity and the highest sensitivity as $87.6 \%$ was shown by S\&L.(19)

This study showed higher sensitivity was obtained if we used our cut-off than literature cut-off, except for S\&L. The highest sensitivity and specificity were obtained by G\&K (sensitivity $90.0 \%$, specificity 92.0\%) and RDWI (sensitivity $88.0 \%$, specificity $92.0 \%$ ) (Table 2). Miri-Monghaddam determined their own cut-off in Iran population, and that study showed that G\&K index showed the highest sensitivity (84\%) and specificity (84\%) to differentiate iron deficiency anemia and beta trait thalassemia.(13)

In this study, the highest accuracy was obtained by G\&K index and RDWI, 91.1\% and 90.9\% respectively (Table 3). A study by Miri-Monghaddam showed that the highest accuracy of hemoglobinopathy was obtained by G\&K index (AUC 90.9\%)(13), whereas Niazi's study showed that the highest accuracy was obtained by RDWI (AUC $88.4 \%$ \%).(20)

In this study, there were 10 of 101 subjects $(9.9 \%)$ diagnosed as hemoglobinopathy but could not be detected using G\&K or RDWI. These 10 subjects consisted of 5 subjects with beta thalassemia trait, 3 subjects with $\mathrm{HbH}$ disease, and 2 subjects with beta-thalassemia/HbE double heterozygote. There were 2 subjects with beta-thalassemia/ 
$\mathrm{HbE}$ double heterozygote in this study, but both subjects could not be detected have a hemoglobinopathy with all formula that we studied, except S\&L. There were 3 of 6 subjects of all $\mathrm{HbH}$ disease subjects that could be detected by RDWI or G\&K, but a greater number of these subjects could be detected by RBC (83.3\%). There were 2 other subjects that could not be detected have a hemoglobinopathy using RDWI, $1 \mathrm{HbE}$ trait subject and 1 beta thalassemia trait subject.

There were $75 \%$ subjects with combination of hemoglobinopathy and iron deficiency that could be correctly predicted having a hemoglobinopathy using RBC count and G\&K index (Table 4). Urrechaga found there were $19.5 \%$ of subjects with combination of hemoglobinopathy and iron deficiency that could not be detected have a hemoglobinopathy and were classified as iron deficiency anemia. It would be more difficult to detect hemoglobinopathy by erythrocyte indices calculation if iron deficiency was also present.(21) It might be due to lower RBC count and hemoglobin concentration which were found if iron deficiency was present with hemoglobinopathy as explained above would influence the result of the calculation.

There were 30 subjects that could not be excluded for the possibility of alfa trait thalassemia. This was classified based on undetectable $\mathrm{HbH}$ inclusion body and normal/high ferritin level in subjects with microcytic hypochromic anemia and normal/slightly low $\mathrm{HbA}_{2}$. $\mathrm{HbH}$ inclusion body is important marker to help the diagnosis of alpha thalassemia. In some cases, $\mathrm{HbH}$ might not be detected. In one alpha gene deletion $(-\alpha / \alpha \alpha)$ or two gene deletion trans type $(-\alpha /-\alpha) \mathrm{HbH}$ is more difficult to be found and the MCV or the RBC usually show a closer value to the reference range compared to two alpha gene deletion cis type $(--/ \alpha \alpha) .(22)$ Using our cut-off, there were still $3.33-83.3 \%$ possibilities of having alpha trait thalassemia in group of subjects with alpha thalassemia could not be excluded (Table 5). To confirm this, DNA analysis is required.

\section{Conclusion}

This study concluded RDWI and G\&K with our own cut-off, 228 and 73, respectively, showed the highest accuracy, sensitiviy and specificity for hemoglobinopathy screening in Indonesia. The presence of iron deficiency in hemoglobinopathy could decrease the sensitivity of screening. Therefore attention should be kept for the possibility of hemoglobinopathy in case there is not a good response in erythrocyte indices or their calculation after receiving adequate iron therapy.

\section{References}

1. Bain BJ. Hemoglobinopathy diagnosis. 2nd ed. Massachusetts: Blackwell Publishing; 2006.

2. Batebi A, Pourreza A, Esmailian R. Discrimination of betathalassemia minor and iron deficiency anemia by screening test for red blood cell indices. Turk J Med Sci. 2012; 42: 275-80.

3. Bordbar E, Taghipour M, Zucconi BE. Reliability of different RBC indices and formulas in differentiating between $\beta$-thalassemia minor and other microcytic hypochromic cases. Mediterr J Hematol Infect Dis. 2015; 7: e2015022. doi: doi: 10.4084/MJHID.2015.022.

4. Danjou F, Anni F, Galanello R. Beta-thalassemia: from genotype to phenotype. Hematologica. 2011; 96: 1573-5.

5. DeLoughery TG. Microcytic anemia. T Engl J Med. 2014; 371:132431.

6. Dirjen Bina Pelayanan Medik, Kementerian Kesehatan Republik Indonesia. Pencegahan Thalassemia (Hasil Kajian HTA Tahun 2009). Jakarta: Kementrian Kesehatan RI; 2010.

7. Janus J, Moerschel S. Evaluation of anemia in children. Am Fam Physician. 2010; 81: 1462-71.

8. Khatri A, Kavatkar A, Puranik S. Evaluation of red cell distribution width (RDW) and other indices in microcytic anemias. Med J West India. 2013: 41: 76-80

9. Martin A, Thompson AA. Thalassemias. Pediatr Clin N Am. 2013; 60: 1383-91.

10. Mc Kenzie. Anemia of defective heme synthesis. In: Balado D, editor. Textbook of hematology. 2nd ed. Baltimore: William and Wilkins;1996. p.121-46.

11. Miri-Monghaddam E, Sargolzaie N. Cut off determination of discrimination indices in differential diagnosis between iron deficiency anemia and $\beta$-thalassemia minor. Int J Hematol Oncol Stem Cell Res. 2014; 8: 27-32.

12. Mousa AO. Types of anemias with low MCV using Mentzer Index and $\mathrm{RBC}$ count among patients seen in Basrah Al-Sadir Teaching Hospital. Med J Babylon. 2014; 11: 292-6.

13. Narchi H, Basal RB. Comparison of erythrocyte indices to differentiate between iron deficiency and $\alpha$-thalassemia in children with micrositosis and/or hypochromia. East Mediterr Health J. 2010; 9: 966-71.

14. Niazi M, Tahir M, Raziq F, Hameed A. Usefulness of red cell indices in differentiating microcytic hypochromic anemias. Gomal J Med Sci. 2010; 8: 125-9.

15. Nesa A, Tayab A, Sultana T, Khondker L, Rahman Q, Karim A, et al. RDWI is better discriminant than RDW in differentiation of iron deficiency anaemia and beta thalassemia trait. Bangladesh J Child Health. 2009; 33: 100-3.

16. Okan V, Cigiloglu A, Cifci S, Yilmaz M, Pehlivan M. Red cell indices and functions differentiating patients with the $\beta$-thalassaemia trait from those with iron deficiency anaemia. J Int Med Res. 2009; 37: 25-30.

17. Rahim F, Keikhaei B. Better differential diagnosis of iron deficiency anemia from beta-thalassemia trait. Turk J Hematol. 2009; 26: 13845. 
18. Rathod DA, Kaur A, Patel V, Patel K, Kabrawala R, Patel V, et al. Usefulness of cell counter-based parameters and formulas in detection of $\beta$-thalassemia traits in areas of high prevalence. Am J Clin Pathol. 2007; 128: 585-9.

19. Rund D, Filon D, Strauss N, Rachmilewitz EA, Oppenheim A, et al. Mean corpuscular volume of heterozygotes for beta-thalassemia correlates with the severity of mutations. Blood. 1992; 79: 23843.

20. Sirachainan $N$, Lamsiriak $P$, Charoenkwan $P$, Kadegasem $P$, Wongwerawattanakoon P, Sasanakul W, et al. New mathematical formula for differentiating thalassemia trait and iron deficiency anemia in thalassemia prevalent area: a study in healthy school-age children. Southeast Asian J Trop Med Public Health. 2014; 45: 17482.

21. Urrechaga E, Aguirre U, Izquierdo S. Multivariable discriminant analysis for the differential diagnosis of microcytic anemia. Anemia 2013: 457834. doi: 10.1155/2013/457834.

22. Vehapoglu A, Ozgurhan G, Demir AD, Uzuner S, Nursoy MA, Turkmen S, et al. Hematological indices for differential diagnosis in $\beta$ thalassemia trait and iron deficiency anemia. Anemia. 2014: 576738. doi: 10.1155/2014/576738.

23. Wang C, Beganyi L, Fernandes BJ. Measurements of red cell parameters in $\alpha$-thalassemia trait: correlation with the genotype. Lab Hematol. 2000; 6: 163-6. 